\title{
RESPONSE OF CULTURED NORMAL CANINE MAMMARY EPITHELIAL CELLS TO DERACOXIB-DOXORUBICIN COMBINATION
}

\author{
Tulay BAKIREL ${ }^{1}$, Fulya Ustun AlKan ${ }^{1 *}$, Oya Ustuner ${ }^{1}$, Suzan $_{\text {ÇInAR }}{ }^{2}$, Ceren Anlas $^{1}$ \\ and Ataman BILGE SARI ${ }^{1}$ \\ ${ }^{1}$ Department of Pharmacology and Toxicology, Faculty of Veterinary Medicine, Istanbul \\ University, Istanbul, Turkey; ${ }^{2}$ Department of Immunology, Aziz Sancar Experimental \\ Medicine Research Institute, Istanbul University, Istanbul, Turkey
}

(Received 22 September 2016; accepted 4 April 2017)

\begin{abstract}
Currently, there is a growing interest in combining anticancer drugs with the aim to improve outcome in patients suffering from tumours and reduce the long-term toxicity associated with the current standard of treatment. In this study, we evaluated the possible role of deracoxib against the toxicity of doxorubicin on normal canine mammary epithelial cells. The effect of deracoxib and doxorubicin combination on cell viability was determined by MTT assay. Apoptosis was characterised by flow cytometry. Cell nitrite concentrations were measured with the Griess reaction. Deracoxib $(50$ and $100 \mu \mathrm{M})$ treatment decreased the cytotoxic action of doxorubicin at $0.9 \mu \mathrm{M}$ in the cells, from $33.63 \%$ to $13.4 \%$ and $25.82 \%$, respectively. Our results also showed that the reverse effect of deracoxib on doxorubicin-induced cytotoxic activity in the cells was associated with a marked (3.04- to 3.57-fold) decrease in apoptosis. In additional studies identifying the mechanism of the observed effect, deracoxib exhibited an activity to prevent doxorubicin-mediated overproduction of nitric oxide in the cells. Our in vitro study results indicate that deracoxib $(50$ and $100 \mu \mathrm{M})$ can be beneficial in protecting normal cells from the toxic effect of doxorubicin in conjunction with apoptosis by the modulation of nitric oxide production.
\end{abstract}

Key words: Deracoxib, doxorubicin, cell viability, apoptosis, nitric oxide

Mammary tumours rank as the second most common neoplasms in dogs after skin tumours (Rai et al., 2014). The occurrence of malignant forms is reported to vary from 26 to $73 \%$, carcinoma being the most common malignant type (Karayannopoulou et al., 2005). However, most reports on canine mammary tumours focus on the histopathogenic aspects of the lesions, while the mechanisms of progression and the biological behaviour of the disease are not well understood. Therefore, information concerning the prognosis and treatment options

*Corresponding author; E-mail: fustun@istanbul.edu.tr; Phone: 0090 (212) 473-7070; Fax: 0090 (212) 473-7241 
of canine mammary tumours is scarce and very limited (Pereira et al., 2009). Currently, there is no curative therapy especially for metastatic mammary tumours. Surgical excision still remains the treatment of choice for canine mammary tumours, although it alone yields unsatisfactory results in dogs with malignant mammary tumours exhibiting lymphatic or vascular invasion (Simon et al., 2006). Chemotherapy is recognised as one of the few treatment options that can be effective in controlling the distant spread of the disease, so it may help to increase the disease-free interval or the survival time (Karayannopoulou et al., 2001). Among the many types of chemotherapeutic drugs, doxorubicin (DOX), either alone or in combination with other agents, is a commonly used anticancer drug for the treatment of these tumours in veterinary oncology. It is known that the lack of success of chemotherapy with DOX as a result of resistance development and dose-limiting toxicity is a major issue in the clinical management of the neoplasms (Pagnini et al., 2000; Todorova et al., 2005). For this reason, alternative remedies are needed to increase the therapeutic efficacy and minimise the systemic toxicity of the chemotherapeutic agent against mammary tumours in dogs. In recent years, extensive research has been focused on the use of nonsteroidal anti-inflammatory drugs (NSAIDs), which have anti-tumourigenic and chemotherapeutic effects in several different types of cancer, in combination with anticancer drugs as a novel treatment option (Wolfesberger et al., 2006; van Wijngaarden et al., 2007; Falandry et al., 2009).

COX-2 is overexpressed along the continuum of oncogenesis and is likely to be a key player in a number of biologic pathways leading to cancer. Current evidence indicates that COX-2 promotes tumour-specific angiogenesis, inhibits apoptosis, and induces proangiogenic factors such as VEGF and inducible nitrogen oxide synthase promoter (iNOS) (Koki and Masferrer, 2002). Recent studies have reported that COX-2 was overexpressed in canine mammary tumours compared with normal mammary tissue. Since COX-2 expression and staining intensity correlate with the clinical and histologic features of mammary tumour malignancy, it has been hypothesised that COX-2 inhibitors may be useful in the treatment of mammary tumours in dogs (Souza et al., 2009). This hypothesis is supported by the results of various experimental and clinical studies indicating that NSAIDs, particularly the selective COX-2 inhibitors, have chemotherapeutic potential in mammary tumours (Alshafie et al., 2000; Rao and Knaus, 2008; Ustun Alkan et al., 2012). Although the significance of these inhibitors is well established, the mechanisms underlying their chemopreventive and chemotherapeutic actions are largely unknown. Indeed, there is evidence suggesting that these actions of COX-2 inhibitors have been attributed to both COX-dependent and COX-independent mechanisms relating to the induction of cell apoptosis and the inhibition of angiogenesis and cell invasion/migration (Alshafie et al., 2000; Awara et al., 2004; Patel et al., 2005; Rao and Knaus, 2008). Additional studies have indicated that these inhibitors may also sensitise cancer cells to the antipro- 
liferative effects of cytotoxic drugs by different molecular mechanisms such as inhibition of Pgp expression and induction of DNA hypermethylation (Hilovska et al., 2015). Therefore, combining COX-2 inhibitors with chemotherapeutic drugs may allow for the use of a lower dose of cytotoxic drugs and may also enhance the effectiveness of therapy.

One such NSAID is the selective COX-2 inhibitor Deracoxib (DER), which is widely used in veterinary medicine for the control of pain and inflammation associated with osteoarthritis and orthopaedic surgery in dogs (Roberts et al., 2009). Studies conducted by us have shown that DER at high concentrations $(500-1000 \mu \mathrm{M})$ has anticancer activity against the canine mammary cancer cell line CMT-U27 (Ustun Alkan et al., 2012, 2014). Also, our chemo-combination study has shown that DER at low concentrations $(50-250 \mu \mathrm{M})$ enhanced the antiproliferative effect of DOX in conjunction with the induction of apoptosis and changes in the cell cycle of the CMT-U27 cell line (Bakirel et al., 2016). It is known that the rationale underlying combination cytotoxic chemotherapy has been to co-administer drugs that work by different molecular mechanisms, thereby increasing tumour cell killing without significant toxicity to normal cells (Al-Lazikani et al., 2012). In this context, there is one published report demonstrating the synergistic cytotoxic effects of DOX in combination with DER on canine mammary carcinoma cells, but possible effects of the combination on normal canine cells have not been investigated to date. Therefore, we decided to investigate whether the selective COX-2 inhibitor drug DER could be able to restore the response of a chemotherapeutic agent (DOX) on normal canine mammary epithelial cells.

\section{Materials and methods}

\section{Cell culture and chemicals}

Canine mammary epithelial cells were isolated from the mammary gland of a healthy female dog as described previously with minor modifications (Wolfe et al., 1986; Smalley, 2010) during surgical treatment at the Department of Obstetrics and Gynaecology, Faculty of Veterinary Medicine of Istanbul University. Briefly, mammary gland tissue was rinsed in antibiotics $(100 \mathrm{IU} / \mathrm{ml}$ penicillin, $100 \mu \mathrm{g} / \mathrm{ml}$ streptomycin and $2.5 \mu \mathrm{g} / \mathrm{ml}$ amphotericin B) and then transferred to a sterile glass Petri dish and minced with scalpels until the glands were rendered to a paste. For dissociation, the mammary tissue was transferred to a tube containing collagenase $(0.35 \%)$ and incubated at $37{ }^{\circ} \mathrm{C}$ for $2-6 \mathrm{~h}$. After dissociation, the cells were centrifuged at $350 \times g$ for 5 min and the supernatant was discarded. The pellet was resuspended with Hanks' Balanced Salt Solution supplemented with 5\% fetal bovine serum (FBS) and ammonium chloride solution and centrifuged at $350 \times \mathrm{g}$ for $5 \mathrm{~min}$. As a result, the pellet contained epithelial cell organoids and fibroblasts. After pre-plating to remove fibroblasts, the organoids were 
resuspended in Epicult medium (Stemcell Tech, Canada) supplemented with epidermal growth factor (EGF) and transferred to a flask. The cultures were incubated at $37{ }^{\circ} \mathrm{C}$ in a humidified atmosphere of $5 \% \mathrm{CO}_{2}$. Over a period of several (5-7) days, the epithelial cells mobilised and spread out from the organoids to form a monolayer. When primary cultures reached confluency, they were subcultured by first washing the adherent cells with DMEM-F12 medium supplemented with $10 \% \mathrm{FBS}$, followed by incubation with $0.25 \%$ trypsin-EDTA solution. Once the cells had detached from the flask, an equal volume of DMEM-F12 medium was added and the cell suspension was centrifuged at $350 \times g$ for $5 \mathrm{~min}$. Collected cells were then reseeded into the flasks and subcultured every 2-3 days. DER was a generous gift from Novartis Pharmaceuticals Inc. (Basel, Switzerland). All reagents were purchased from Sigma-Aldrich (St. Louis, MO, USA) except Epicult medium (Stemcell Technologies, Tokyo, Japan). DOX and DER were dissolved in DMEM-F12 and sterile dimethyl sulphoxide (DMSO), respectively, and further serial dilutions of both drugs were made with DMEM-F12. The final DMSO concentration did not exceed $0.1 \%$ (and had no effect on cell growth) in any experimental group, and this condition was used as control in each experiment (all groups comprised 0.1\% DMSO). All of the stock solutions were kept at a temperature of $-20^{\circ} \mathrm{C}$.

\section{Cell viability assay}

Cell viability assay was performed to determine the effects of DOX and DER on the viability of canine mammary epithelial cells. For this purpose, cells were seeded at a density of $2 \times 10^{4}$ cells/100 $\mu 1$ in 96-well flat bottom microtitre plates (Jet Biofil, Canada) in triplicate and incubated in a humidified atmosphere at $37{ }^{\circ} \mathrm{C}$ under $5 \% \mathrm{CO}_{2}$ and $95 \%$ air to allow cell adhesion. After $24 \mathrm{~h}$ incubation, medium was removed and cells were treated with various concentrations of $\operatorname{DOX}(0.9 \mu \mathrm{M})$ and DER $(50,100$ and $250 \mu \mathrm{M})$ for $72 \mathrm{~h}$. The concentrations for DOX and DER were chosen on the basis of our previous reports about the effects of these drugs on the in vitro viability of canine mammary tumour cells (Ustun Alkan et al., 2014; Bakirel et al., 2016). In addition, the tested concentration of $\operatorname{DOX}(0.9 \mu \mathrm{M})$ was within the range of the clinically relevant concentration and the chosen concentrations of DER $(50-250 \mu \mathrm{M})$ cannot lead to toxicity in canine mammary tumour cells (Bakirel et al., 2016). Cell viability was assessed using a cell proliferation kit (MTT, Roche, Germany) according to the manufacturer's instructions. Briefly, $10 \mu \mathrm{l}$ of MTT solution $[5 \mathrm{mg} / \mathrm{ml}$ in phosphate buffered saline (PBS)] was added to each well and incubated for $4 \mathrm{~h}$ at $37^{\circ} \mathrm{C}$ in a $\mathrm{CO}_{2}$ incubator. The purple water-insoluble formazan salt was then dissolved with $10 \%$ SDS in $0.01 \mathrm{M} \mathrm{HCl}$ and incubated overnight in a humidified $5 \% \mathrm{CO}_{2}$ atmosphere. The optical densities (OD) of the wells were measured at $550 \mathrm{~nm}$ by a microplate reader (ELx800, Biotek Instruments, USA). The effect of each compound on growth inhibition was assessed as percent cell viability where control 
cells were taken as $100 \%$ viable. Subsequently, we tested $0.9 \mu \mathrm{M}$ of DOX with 50,100 and $250 \mu \mathrm{M}$ of DER in combination to determine the possible effect of DER against DOX toxicity on normal canine mammary epithelial cells. The cells were treated with DOX and DER for $72 \mathrm{~h}$ and the effects of the combined agents on cell viability were evaluated according to the MTT assay as described above.

\section{Apoptosis assay}

An apoptosis assay was performed to determine the effects of DER and DOX on apoptosis in normal canine mammary epithelial cells. Flow cytometric analyses of phosphatidylserine exposure were quantitatively performed using the Annexin V-fluorescein isothiocyanate (FITC) Apoptosis Detection Kit (BD Bioscience, San Jose, CA). The cells were cultured at a density of $2 \times 10^{5} / \mathrm{ml}$ in 24-well flat bottom microtitre plates (Jet Biofil, Korea) and treated with DOX $(0.9 \mu \mathrm{M})$ and DER $(50-250 \mu \mathrm{M})$ alone or in combination as described for the MTT assay. The cells were trypsinised $72 \mathrm{~h}$ after the treatment and washed twice each with ice-cold phosphate-buffered saline (PBS) consisting of $0.01 \mathrm{M}$ phosphate buffer, $0.0027 \mathrm{M}$ potassium chloride and $0.137 \mathrm{M}$ sodium chloride, and then resuspended in $100 \mu$ l binding buffer [0.1 M Hepes/ $\mathrm{NaOH}(\mathrm{pH} 7.4), 1.4 \mathrm{M} \mathrm{NaCl}$, $25 \mathrm{mM} \mathrm{CaCl}_{2}$ ] supplemented with $5 \mu \mathrm{l}$ of FITC-Annexin $\mathrm{V}$ and $5 \mu \mathrm{l}$ of propidium iodide (PI). The cell suspension was gently vortexed and incubated for $15 \mathrm{~min}$ at room temperature in the dark. Following incubation, $400 \mu \mathrm{l}$ of binding buffer was added to each tube and then analysed within $1 \mathrm{~h}$ on a FACScan flow cytometer (BD Biosciences) using the standard optics for detecting FL1 (FITC) and FL3 (PI). Data were analysed with the CellQuest WinMDI software (BD Biosciences, San Jose, CA). The apoptotic index (\%) was calculated as the sum of early and late apoptotic cells.

\section{Nitric oxide assay}

Since nitric oxide (NO) is very labile, its direct measurement in biological samples is difficult. In aqueous solution, NO reacts with molecular oxygen and accumulates in the supernatants of cells as nitrite $\left(\mathrm{NO}_{2}^{-}\right)$ions. This stable oxidation end product is readily measured in biological samples and has been used in vitro and in vivo as an indicator of NO production (Akdeniz et al., 2004). The concentration of nitrite in the supernatants of cells was taken as a measure of the oxidation product of $\mathrm{NO}$ and quantified by a colorimetric assay based on the Griess reaction. For this purpose, the cells were cultured at a density of $2 \times$ $10^{5} / \mathrm{ml}$ in 24-well flat bottom microtitre plates and treated with DOX $(0.9 \mu \mathrm{M})$ and DER (50-250 $\mu \mathrm{M})$ alone or in combination as described for the apoptosis assay. At the end of the 72-h incubation period the supernatants were collected. Briefly, $100 \mu \mathrm{L}$ of supernatant from each well was mixed with $100 \mu \mathrm{L}$ of Griess reagent (1\% sulphanilamide in 5\% phosphoric acid and $0.1 \%$ naphthylethyl- 
enediamine dihydrochloride in water) in a separate 96-well plate. After a 5-min incubation at room temperature, the optical density was determined at $530 \mathrm{~nm}$ with a microplate reader and $\mathrm{NO}_{2}$ levels were measured by comparison to the sodium nitrite $\left(\mathrm{NaNO}_{2}\right)$ standard curve (Chen et al., 2008).

\section{Statistical analysis}

All experiments were run in triplicate and the results were expressed as the mean \pm SE. The values were initially subjected to one-way ANOVA, which revealed significant differences between groups, followed by Duncan's test, which revealed significant differences between three sample means (SPSS 11.5 statistical package, Chicago, IL). A difference in the mean with P values of 0.05 or less was considered to be statistically significant.

\section{Results}

\section{Cell viability assay}

To determine the effects of DOX and DER as single agents on cell viability of normal canine mammary epithelial cells, MTT assay was performed. DOX at the concentration of $0.9 \mu \mathrm{M}$ was found to significantly $(\mathrm{P}<0.05)$ inhibit the viability (33.63\%) of the cells after 72-h incubation. At the same time, DER (50$250 \mu \mathrm{M})$ alone had no significant effect $(\mathrm{P}>0.05)$ on the cell viability of normal canine mammary epithelial cells (Fig. 1). These results suggest that DER concentrations below $\leq 250 \mu \mathrm{M}$ were non-toxic to the cells. Thus, the cells were treated with DER in concentrations ranging from 50 to $250 \mu \mathrm{M}$ for all follow-up experiments. Subsequently, we tested $0.9 \mu \mathrm{M}$ of DOX in combination with 50,100 and $250 \mu \mathrm{M}$ of DER to determine whether DER prevents the cytotoxic effect of DOX on canine mammary epithelial cells. As shown in Fig. 1, DER prevented the cytotoxic effect of DOX $(0.9 \mu \mathrm{M})$ on canine mammary epithelial cells. The influence of DER on the cytotoxic effect of DOX $(0.9 \mu \mathrm{M})$ appeared to be moderately dose independent, and the strongest prevention, approaching $86.6 \%$ (cell viability), was observed with the combination of DOX at $0.9 \mu \mathrm{M}$ and DER at $50 \mu \mathrm{M}(\mathrm{P}<0.05)$. Also, DER at $100 \mu \mathrm{M}$ concentration decreased the cytotoxic activity of DOX $(0.9 \mu \mathrm{M})$ in canine mammary epithelial cells, which increased the proportion of viable cells from $66.37 \%$ to $74.18 \%(\mathrm{P}<0.05)$.

\section{Apoptosis assay}

In order to elucidate whether the proliferative/cytotoxic effects of DER and DOX alone and in combination on canine mammary epithelial cells were mediated via an apoptotic pathway, apoptotic activities were measured by flow cytometry. The apoptosis assay was performed using concentrations of DOX 
$(0.9 \mu \mathrm{M})$ and DER $(50-250 \mu \mathrm{M})$ that cannot lead to toxicity. Treatment with DOX $(0.9 \mu \mathrm{M})$ alone induced $36.24 \%$ and DER (at $50 \mu \mathrm{M}, 100 \mu \mathrm{M}$ and $250 \mu \mathrm{M}$ ) induced $4.99 \%, 22.74 \%$ and $27.74 \%$ early apoptosis and $4.32 \%, 5.85 \%$ and, 7.13\% late apoptosis, respectively, in canine mammary epithelial cells (Fig. 2). Combined treatment with DOX and DER $(50 \mu \mathrm{M}$ and $100 \mu \mathrm{M})$ significantly $(\mathrm{P}<$ 0.001 ) decreased the apoptosis index (in terms of the sum of early and late apoptotic cells; from $36.24 \%$ to $10.15 \%$ and $11.93 \%$, respectively), as compared with that caused by DOX. Quantification and statistical analysis of the results obtained by flow cytometry for each condition is shown in Fig. 3 and Table 1.

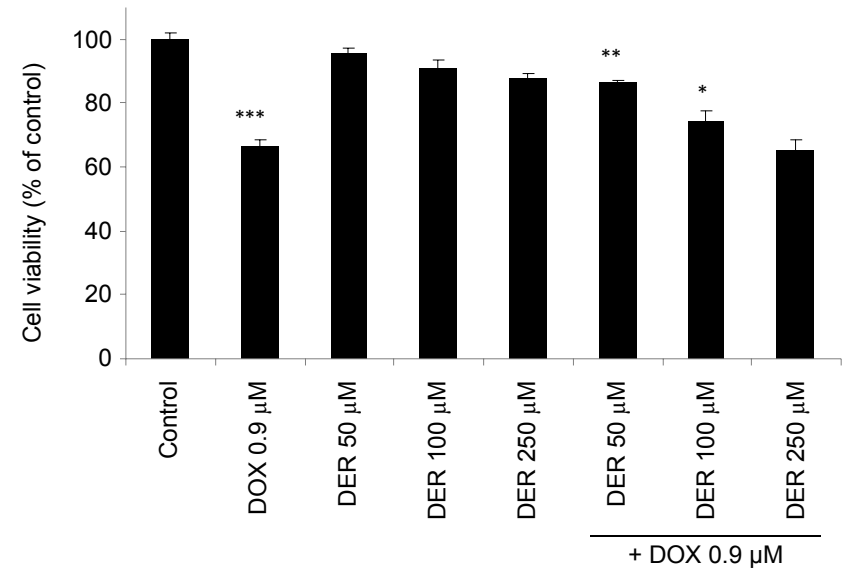

Fig. 1. Effect of doxorubicin (DOX) and deracoxib (DER) on the viability of normal canine mammary epithelial cells. Cells were incubated with DOX and DER and with their combination at the indicated concentrations for $72 \mathrm{~h}$. Cell viability was measured by MTT assay. Values are expressed as the mean percentage of cell viabilities \pm standard error (SE) of three independent experiments. DOX $(0.9 \mu \mathrm{M})$ was compared to the control group. Combination treatments were compared to the DOX-treated $(0.9 \mu \mathrm{M})$ group. ${ }^{*} \mathrm{P}<0.05,{ }^{* *} \mathrm{P}<0.01,{ }^{* * *} \mathrm{P}<0.001$

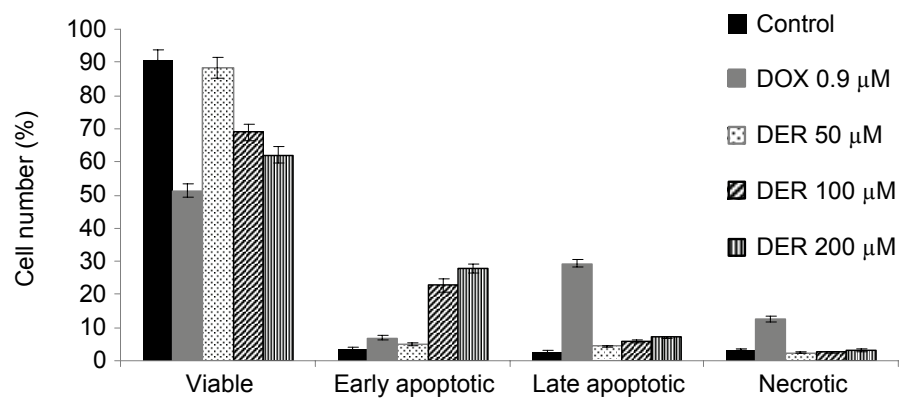

Fig. 2. Effects of doxorubicin (DOX) and deracoxib (DER) treatment on apoptosis of normal canine mammary epithelial cells. The number of viable, early apoptotic, late apoptotic and necrotic cells due to treatment with DOX and DER for $72 \mathrm{~h}$. The experiment was conducted in three replicates. Data are expressed as the mean \pm standard error (SE). DOX $(0.9 \mu \mathrm{M})$ was compared to the control group. Combination treatments were compared to the DOX-treated $(0.9 \mu \mathrm{M})$ group 

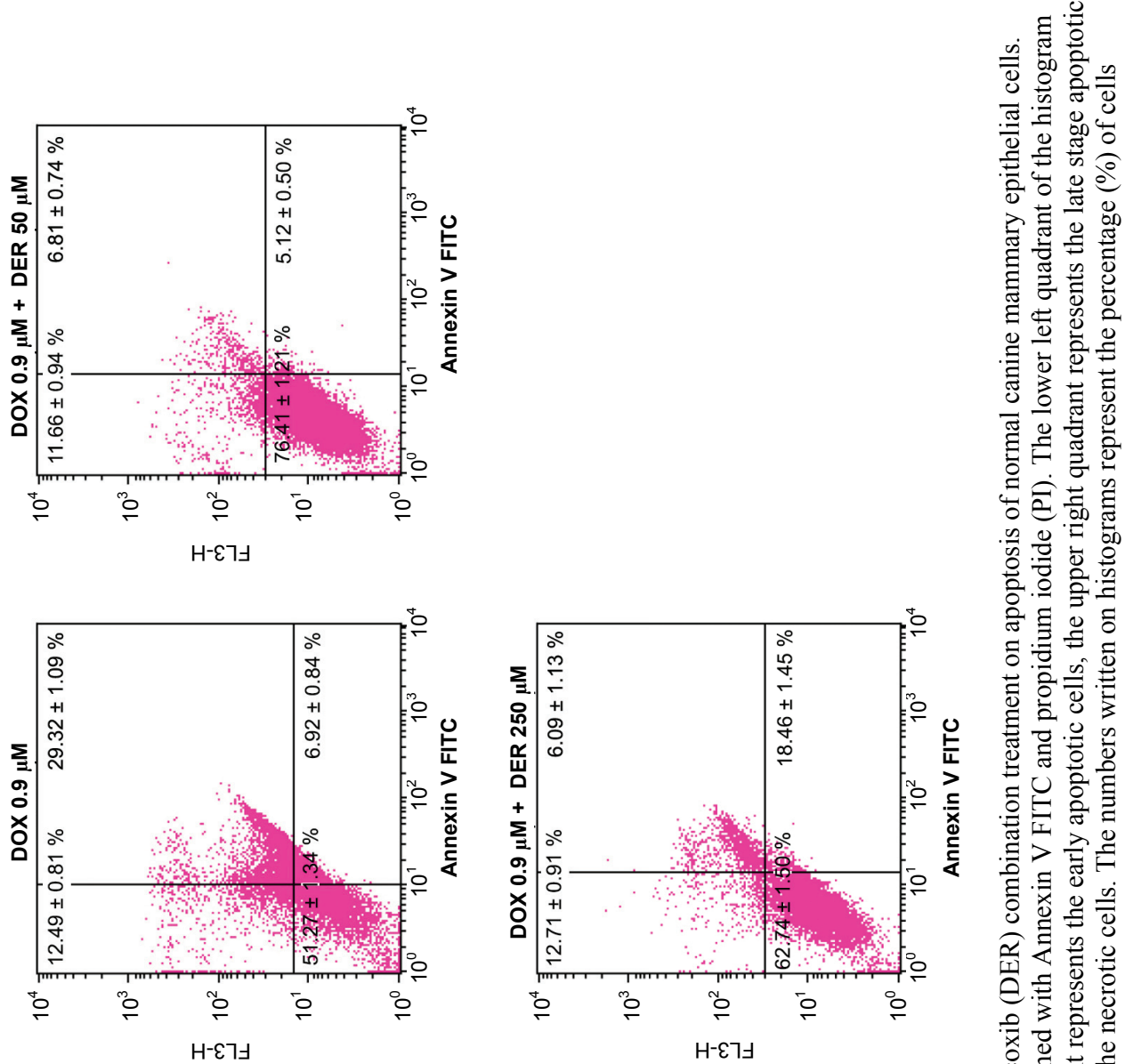

늉. 을

完 $\Xi$

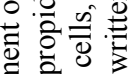

苛

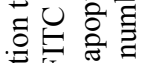

学东

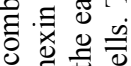

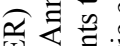

背

으웜

엉
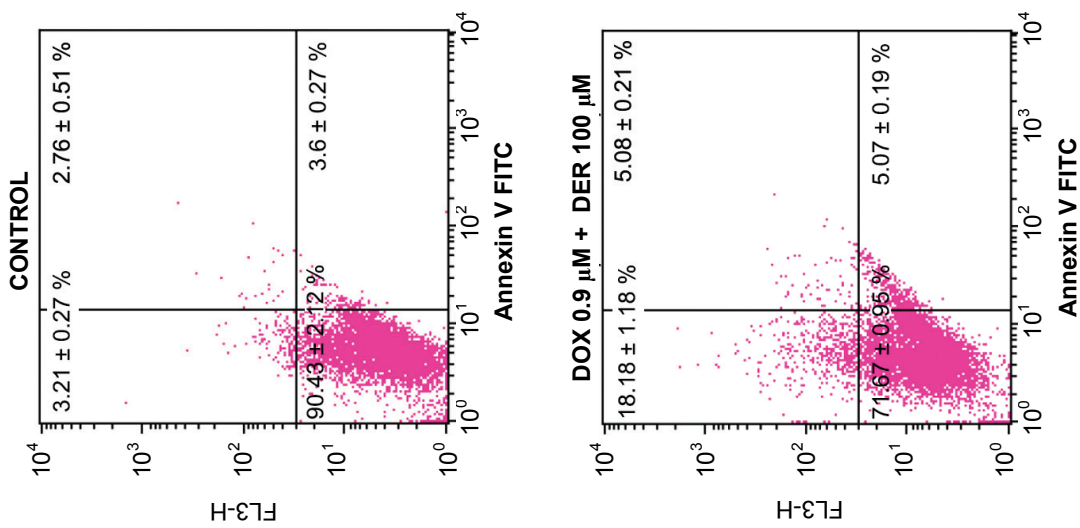

语的

च 힘

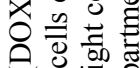

卷

능

두원

해을

ऽ टे

过. 离吾

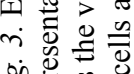

这这 
Table 1

Apoptotic index values of canine mammary epithelial cells after 72-h exposure to DOX and DER combination

\begin{tabular}{lc}
\hline Concentrations of drugs ${ }^{\mathrm{a}}(\mu \mathrm{M})$ & Apoptotic index $(\%)$ \\
\hline Control & $6.36 \pm 0.24$ \\
DOX 0.9 & $36.24 \pm 0.25$ \\
DOX 0.9 + DER 50 & $10.15 \pm 0.023^{* * *}$ \\
DOX 0.9 + DER 100 & $11.93 \pm 0.24^{* * *}$ \\
DOX 0.9 + DER 250 & $24.55 \pm 0.32^{* * *}$
\end{tabular}

${ }^{\mathrm{a}} \mathrm{DOX}=$ doxorubicin; $\mathrm{DER}=$ deracoxib. Each value represents the mean $\pm \mathrm{SE}$ of three experiments. ${ }^{* * *} \mathrm{P}<0.001$ compared to DOX

Nitric oxide assay

In order to study the role of NO production in DOX-induced apoptosis, the concentration of nitrite in the supernatants of cells was measured. The level of $\mathrm{NO}_{2}$ in cells exposed to DOX $(0.9 \mu \mathrm{M})$ was increased prominently $(\mathrm{P}<0.001)$; in contrast, the levels of $\mathrm{NO}_{2}$ did not differ significantly between the DERtreated cells in comparison with the control. However, with the combination of $\operatorname{DOX}(0.9 \mu \mathrm{M})$ with DER (especially at low concentrations, 50 and $100 \mu \mathrm{M})$ the levels of $\mathrm{NO}_{2}$ were significantly $(\mathrm{P}<0.05)$ decreased when compared with DOX $(0.9 \mu \mathrm{M})$ alone (Fig. 4).

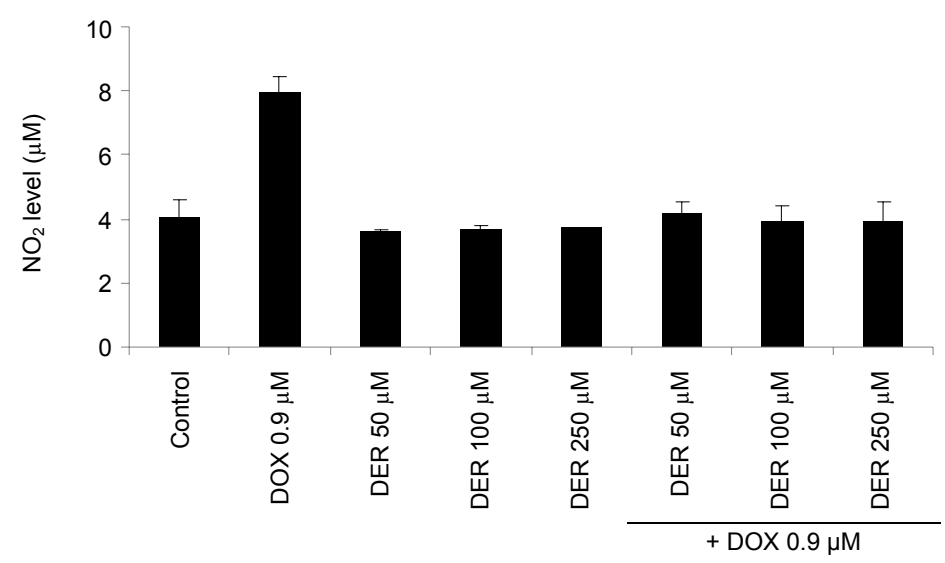

Fig. 4. Effect of doxorubicin (DOX) and deracoxib (DER) treatment on $\mathrm{NO}_{2}$ levels of normal canine mammary epithelial cells. Cells were incubated with DOX and DER and with their combination at the indicated concentrations for $72 \mathrm{~h}$. $\mathrm{NO}_{2}$ levels were measured by Griess reaction.

Values are expressed as the mean percentage of cell viabilities \pm standard error (SE) of three independent experiments. DOX $(0.9 \mu \mathrm{M})$ was compared to the control group. Combination treatments were compared to the DOX-treated $(0.9 \mu \mathrm{M})$ group 


\section{Discussion}

Chemotherapeutic agents used in current clinical practice have played a significant role in reducing mortality/morbidity and in increasing the quality of life of both companion animals and humans (Gustafson and Page, 2013). However, most anticancer drugs have a narrow therapeutic index, develop multidrug resistance and present unacceptable side effects to healthy tissues. These limitations of conventional chemotherapeutic strategies frequently result in suboptimal dosing, treatment delay or discontinuance, and reduced patient compliance to therapy (Ismael et al., 2008). Therefore, novel therapeutic approaches are needed to both improve the outcome of patients suffering from tumours and to minimise the long-term toxicities associated with the current standard of treatment. Drug development strategies include the evaluation of new drug combinations that may have improved efficacy compared with single agents. By treating a tumour with a combination of drugs which employ different mechanisms of action and have different spectra of normal tissue toxicity, the overall response can be enhanced without an increase in toxicity (Narang and Desai, 2009; Al-Lazikani, et al., 2012).

NSAIDs are among the most widely used medications as analgesics and antipyretics. Currently, there is a growing interest in their antitumour activity and their ability to reduce the risk and mortality of several cancers (Pereg and Lishner, 2005; Wolfesberger et al., 2006; McMillan et al., 2011). A number of both clinical and preclinical studies suggest that the combined use of NSAIDs and conventional therapies may improve patient prognosis (van Wijngaarden et al., 2007; Falandry et al., 2009; Rayburn et al., 2009). Although the underlying mechanisms of action for the effects NSAIDs as adjuvants are fully demonstrated, three primary modes of action have been proposed: chemoprotection, alterations in pharmacokinetics or metabolism, and chemosensitisation (Rayburn et al., 2009). Related studies have shown that especially selective COX-2 inhibitors strengthen the effectiveness of chemotherapy treatment in various tumour types of dogs, including transitional cell carcinoma and osteosarcoma (Wolfesberger et al., 2006; McMillan et al., 2011). Similarly, in our previous study we proved that DER used at 50-250 $\mu \mathrm{M}$ concentrations sensitised canine mammary cancer cells (CMT-U27) to the cytotoxic action of DOX $\left(0.9 \mu \mathrm{M}\right.$, the $\mathrm{IC}_{50}$ for CMT-U27). It was elucidated that DER enhanced the antiproliferative effect of DOX in conjunction with induction of apoptosis by modulation of Bcl-2 expression and changes in the cell cycle of the CMT-U27 cell line (Bakirel et al., 2016). Also, some studies have explored the therapeutic benefit of COX inhibitors against the toxicity of conventional chemotherapeutic agents and have shown that COX-2 inhibitors are able to attenuate the effect of certain cytotoxic agents such as DOX-induced oxidative damage by modulating oxidant status in CMT cells (Rayburn et al., 2009; Ustun Alkan et al., 2014). However, the possible role of 
DER, a highly selective canine COX-2 inhibitor accepted as safe and well tolerated in dogs (Roberts et al., 2009), against the toxicity of DOX, a cytotoxic agent commonly used in veterinary clinical treatments for various cancers (Pagnini et al., 2000), on non-malignant cells is unknown. Our results demonstrated that DER at 50 and $100 \mu \mathrm{M}$ concentrations decreased the cytotoxic action of DOX at $0.9 \mu \mathrm{M}$ in cultured normal canine mammary epithelial cells, from $33.63 \%$ to $13.4 \%$ and $25.82 \%$, respectively. Therefore, we suggest that DER, at concentrations 50 and $100 \mu \mathrm{M}$ that do not affect cell viability, can be beneficial through its ability to enhance the protection of normal cells from chemotherapeutic toxicity. On the other hand, our previous study has demonstrated that under the same experimental conditions DER sensitised canine mammary cancer cells (CMT-U27) to the action of DOX (Bakirel et al., 2016). The discrepancy in cytotoxic activity may depend on the preferential uptake of these drugs in cancer cells to normal cells. Cancerous cells possess structural features such as membrane structure, protein composition and bigger size that are different from those of normal proliferating cells, so it is possible that drug concentrations in the tumour cells are higher than in normal cells (Kunwar et al., 2008; Leth-Larsen et al., 2010). Also, different effects of NSAIDs on normal and cancer cells are attributed to the distinctive nature of these drugs for selectively targeting cancer cells (Ralph et al., 2015). To date, NSAIDs in combination with chemotherapy have been shown to have differential effects on normal cells such as normal mouse embryo cell line and normal primary B cells in comparison with cancer cells (Jastrzebska et al., 2013; Gallouet et al., 2014). However, the molecular and cellular mechanisms underlying the alterations in outcome that occur in response to this combination therapy have not been fully understood. In this study, our results have shown that the reverse effect of DER (especially at 50 and $100 \mu \mathrm{M}$ concentrations) on the anti-proliferative activity induced by DOX alone on normal canine mammary epithelial cells is associated with a marked (3.04-3.57-fold) decrease in apoptosis. We suggest that DER may protect the cells against DOX by inhibiting the apoptotic programme. Also, our results have demonstrated that DOX alone caused late apoptosis rather than early apoptosis. The number of late apoptotic cells was significantly decreased by the addition of DER in a dose-independent manner. An increase in early apoptotic activity indicates that the cells are in a static, non-proliferative state, while an increase in late apoptotic activity suggests that the cells are in the final stages of the apoptotic cycle and that cell death is imminent (Ustun Alkan et al., 2012). Although chemotherapeutic agents may induce apoptosis through the death receptor pathway, the mitochondrial pathway is indicated as the primary pathway in anticancer drug-mediated cell killing (Indran et al., 2011). This pathway, activated by receptor-independent stimulants such as chemotherapeutic agents, proceeds through changes of mitochondrial membrane permeability, leading to the release of pro-apoptotic proteins and the arrest of the bioenergetic function of the organelle (Shi, 2001; Elmore, 2007). It has been re- 
ported that the release of pro-apoptotic proteins is a late event in apoptosis, which occurs once the cells are committed to die (Indran et al., 2011). DOX, which is known to trigger apoptotic cell death, induces apoptosis in normal and tumour cells via distinctly different mechanisms (Meng et al., 2014). In this context, mitochondrial dysfunction and severe inhibition/inactivation of certain mitochondrial system have been implicated as important pathways of apoptosis induced by DOX associated with its remarkable toxicity in normal cells (Mizutani et al., 2005; Octavia et al., 2012). Some studies have suggested that increased oxidative/nitrosative stress associated with an impaired antioxidant defence status plays a critical role in DOX-induced mitochondrial dysfunction (Octavia et al., 2012; Hao et al., 2015). DOX increases mitochondrial superoxide and, consequently, the generation of reactive oxygen species (e.g. $\mathrm{H}_{2} \mathrm{O}_{2}$ ) in endothelial cells, leading to enhanced NO generation (Mukhopadhyay et al., 2009). Elevated production of NO may cause cell death related to the formation of peroxynitrite, which is involved in the inflammatory process (Rehman et al., 2014). Large amounts of NO inhibit DNA synthesis, damage DNA and, hence, induce apoptosis (Ozen et al., 2001). In an experimental model studying the association of NO and apoptosis, Mukhopadhyay et al. (2009) suggested that NO is a major trigger/mediator of DOX-induced apoptotic cell death. In the present study, we found that DOX induced a marked increase of NO generation, by measuring the accumulation of its stable degradation product nitrite in the cells. This result provides additional support for the above-mentioned theory. On the other hand, the DER dose independently attenuated the DOX-induced excess NO production as measured by $\mathrm{NO}_{2}^{-}$level (as well as apoptotic activity) in the cells. We suggest that DER may have a modulatory role in regulating NO production of the cells against DOX. Our observation is consistent with the findings of Ozgocmen et al. (2005), who demonstrated that NSAIDs (e.g. celecoxib and tenoxicam) may reduce nitrite levels, indicating an alteration in the NO pathway. Similarly, Asanuma et al. (2001) reported that the protective effect of some NSAIDs (aspirin, mefenamic acid, indomethacin and ketoprofen) against NOC18-induced apoptosis might be mainly due to their direct NO radical scavenging activities in neuronal cells (Asanuma et al., 2001). Although the mechanisms of the inhibitory effects of NSAIDs against inflammatory mediator and cytotoxic agent induced increases in NO production in cells have not been completely defined (Asanuma et al., 2001; Abou El Hassan et al., 2003) some studies have reported that NSAIDs have a blocking effect on NO production through their inhibiting effects on iNOS (Farivar et al., 1996; Du and Li, 1999; Sanchez de Miguel et al., 1999). In this respect, we suggest that DOX-induced NO production in cultured epithelial cells might be caused by the reactive oxygen species-induced promotion of NF$\kappa \mathrm{B}$ (Schreck et al., 1991; Meyer et al., 1993) and the protective effect of DER against DOX-induced apoptotic nuclear changes might be due mainly to its direct scavenging activity on produced intracellular NO in the epithelial cells. 
In summary, our in vitro study results indicate that DER, especially at low concentrations (50 and $100 \mu \mathrm{M})$ not affecting cell viability, can be beneficial in protecting normal cells from the toxic effect of DOX in conjunction with apoptosis by the modulation of $\mathrm{NO}$ production. We have concluded that the addition of DER $(50-100 \mu \mathrm{M})$ to DOX $(0.9 \mu \mathrm{M})$ therapy may be beneficial in minimising the damage to normal tissues.

\section{Acknowledgements}

This study was supported by TUBITAK (Project no. 108O296). We thank Prof. Bulent Ekiz (Istanbul University, Turkey) for the statistical analyses.

\section{References}

Abou El Hassan, M. A. I., Verheul, H. M. W., Jorna, A. S., Schalkwijk, C., van Bezu, J., van der Vijgh, W. J. F. and Bast, A. (2003): The new cardioprotector monohydroxyethylrutoside protects against doxorubicin-induced inflammatory effects in vitro. Br. J. Cancer. 89, 357-362.

Akdeniz, N., Esrefoglu, M., Keles, M., Karakuzu, A. and Atasoy, M. (2004): Serum interleukin-2, interleukin-6, tumour necrosis factor-alpha and nitric oxide levels in patients with Behcet's disease. Ann. Acad. Med. Singap. 33, 596-599.

Al-Lazikani, B., Banerji, U. and Workman, P. (2012): Combinational drug therapy for cancer in the post-genomic era. Nat. Biotechnol. 30, 679-692.

Alshafie, G. A., Abou-Issa, H. M., Seibert, K. and Harris, R. E. (2000): Chemotherapeutic evaluation of Celecoxib, a cyclooxygenase-2 inhibitor, in a rat mammary tumor model. Oncol. Rep. 7, $1377-1381$.

Asanuma, M., Nishibayashi-Asanuma, S., Miyazaki, I., Kohno, M. and Ogawa, N. (2001): Neuroprotective effects of non-steroidal anti-inflammatory drugs by direct scavenging of nitric oxide radicals. J. Neurochem. 76, 1895-1904.

Awara, W. M., El-Sisi, A. E., El-Sayad, M. E. and Goda, A. E. (2004): The potential role of cyclooxygenase- 2 inhibitors in the treatment of experimentally-induced mammary tumour: does celecoxib enhance the anti-tumor activity of doxorubicin? Pharmacol. Res. 50, 487-498.

Bakirel, T., Ustun Alkan, F., Ustuner, O., Cinar, S., Yildirim, F., Erten, G. and Bakirel, U. (2016): Synergistic growth inhibitory effect of deracoxib with doxorubicin against a canine mammary tumor cell line, CMT-U27. J. Vet. Med. Sci. 78, 657-668.

Chen, L. G., Yang, L. L. and Wang, C. C. (2008): Anti-inflammatory activity of mangostins from Garcinia mangostana. Food Chem. Toxicol. 46, 688-693.

Du, Z. Y. and Li, X. Y. (1999): Inhibitory effects of indomethacin on interleukin-1 and nitric oxide production in rat microglia in vitro. Int. J. Immunopharmacol. 21, 219-225.

Elmore, S. (2007): Apoptosis: A review of programmed cell death. Toxicol. Pathol. 35, 495-516.

Falandry, C., Canney, P. A., Freyer, G. and Dirix, L. Y. (2009): Role of combination therapy with aromatase and cyclooxygenase- 2 inhibitors in patients with metastatic breast cancer. Ann. Oncol. 20, 615-620.

Farivar, R. S., Chobanian, A. V. and Brecher, P. (1996): Salicylate or aspirin inhibits the induction of the inducible nitric oxide synthase in rat cardiac fibroblasts. Circ. Res. 78, 759-768.

Gallouet, A. S., Travert, M., Bresson-Bepoldin, L., Guilloton, F., Pangault, C., Caulet-Maugendre, S., Lamy, T., Tarte, K. and Guillaudeux, T. (2014): COX-2-independent effects of celecoxib sensitize lymphoma B cells to TRAIL-mediated apoptosis. Clin. Cancer Res. 20, 2663-2673. 
Gustafson, D. L. and Page, R. L. (2013): Cancer chemotherapy. In: Withrow, S., Vail, D. and Page, R. (eds) Withrow and MacEwen's Small Animal Clinical Oncology. 5th edition, Elsevier Health Sciences, Missouri. pp. 157-179.

Hao, E., Mukhopadhyay, P., Cao, Z., Erdélyi, K., Holovac, E., Liaudet, L., Lee, W-S., Haskó, G., Mechoulam, R. and Pacher, P. (2015): Cannabidiol protects against doxorubicin-induced cardiomyopathy by modulating mitochondrial function and biogenesis. Mol. Med. 21, 38-45.

Hilovska, L., Jendzelovsky, R. and Fedorocko, P. (2015): Potency of non-steroidal anti-inflammatory drugs in chemotherapy (Review). Mol. Clin. Oncol. 3, 3-12.

Indran, I. R., Tufo, G., Pervaiz, S. and Brenner, C. (2011): Recent advances in apoptosis, mitochondria and drug resistance in cancer cells. Biochim. Biophys. Acta 1807, 735-745.

Ismael, G. F. V., Rosa, D. D., Mano, M. S. and Awada, A. (2008): Novel cytotoxic drugs: Old challenges, new solutions. Cancer Treat. Rev. 34, 81-91.

Jastrzebska, E., Flis, S., Rakowska, A., Chudy, M., Jastrzebski, Z., Dybko, A. and Brzozka, Z. (2013): A microfluidic system to study the cytotoxic effect of drugs: The combined effect of celecoxib and 5-fluorouracil on normal and cancer cells. Microchim. Acta 180, 895-901.

Karayannopoulou, M., Kaldrymidou, E., Constantinidis, T. C. and Dessiris, A. (2001): Adjuvant postoperative chemotherapy in bitches with mammary cancer. J. Vet. Med. A 48, 85-96.

Karayannopoulou, M., Kaldrymidou, E., Constantinidis, T. C. and Dessiris, A. (2005): Histological grading and prognosis in dogs with mammary carcinomas: Application of a human grading method. J. Comp. Pathol. 133, 246-252.

Koki, A. T. and Masferrer, J. L. (2002): Celecoxib: A specific COX-2 inhibitor with anticancer properties. Cancer Control 9, 28-35.

Kunwar, A., Barik, A., Mishra, B., Rathinasamy, K., Pandey, R. and Priyadarsini, K. I. (2008): Quantitative cellular uptake, localization and cytotoxicity of curcumin in normal and tumor cells. Biochim. Biophys. Acta 1780, 673-679.

Leth-Larsen, R., Lund, R. R. and Ditzel, H. J. (2010): Plasma membrane proteomics and its application in clinical cancer biomarker discovery. Mol. Cell. Proteomics 9, 1369-1382.

McMillan, S. K., Boria, P., Moore, G. E., Widmer, W. R., Bonney, P. L. and Knapp, D. W. (2011): Antitumor effects of deracoxib treatment in 26 dogs with transitional cell carcinoma of the urinary bladder. JAVMA 239, 1084-1089.

Meng, X., Zhang, Q., Zheng, G., Pang, R., Hua, T., Yang, S. and Li, J. (2014): Doxorubicin combined with celecoxib inhibits tumor growth of medullary thyroid carcinoma in xenografted mice. Oncol. Lett. 7, 2053-2058.

Meyer, M., Schreck, R. and Baeuerle, P. A. (1993): $\mathrm{H}_{2} \mathrm{O}_{2}$ and antioxidants have opposite effects on activation of NF- Kb and AP-1 in intact cells: aP-1 as secondary antioxidant-responsive factor. EMBO J. 12, 2005-2015.

Mizutani, H., Tada-Oikawa, S., Hiraku, Y., Kojima, M. and Kawanishi, S. (2005): Mechanism of apoptosis induced by doxorubicin through the generation of hydrogen peroxide. Life Sci. 76, 1439-1453.

Mukhopadhyay, P., Rajesh, M., Batkai, S., Kashiwaya, Y., Hasko, G., Liaudet, L., Szabo, C. and Pacher, P. (2009): Role of superoxide, nitric oxide, and peroxynitrite in doxorubicin-induced cell death in vivo and in vitro. Am. J. Physiol. Heart Circ. Physiol. 296, 1466-1483.

Narang, A. S. and Desai, D. S. (2009): Anticancer drug development. In: Lu, Y. and Mahato, R. I. (eds) Pharmaceutical Perspectives of Cancer Therapeutics, 16th edition. Springer Science \& Business Media, New York. pp. 49-92.

Octavia, Y., Tocchetti, C. G., Gabrielson, K. L., Janssens, S., Crijns, H. J. and Moens, A. L. (2012): Doxorubicin-induced cardiomyopathy: From molecular mechanisms to therapeutic strategies. J. Mol. Cell. Cardiol. 52, 1213-1225.

Ozen, S., Usta, Y., Sahin-Erdemli, I., Orhan, D., Gumusel, B., Yang, B., Gursoy, Y., Tulunay, O., Dalkara, T., Bakkaloglu, A. and El Nahas, M. (2001): Association of nitric oxide production and apoptosis in a model of experimental nephropathy. Nephrol. Dial. Transpl. 16, 32-38. 
Ozgocmen, S., Ardicoglu, O., Erdogan, H., Fadillioglu, E. and Gudul, H. (2005): In vivo effect of celecoxib and tenoxicam on oxidant/anti-oxidant status of patients with knee osteoarthritis. Ann. Clin. Lab. Sci. 35, 137-143.

Pagnini, U., Florio, S., Lombardi, P., d'Angelo, D., Avallone, L., Galdiero, M., Iovane, G., Tortora, G. and Pagnini, G. (2000): Modulation of anthracycline activity in canine mammary tumour cells in vitro by medroxyprogesterone acetate. Res. Vet. Sci. 69, 255-262.

Patel, M. I., Subbaramaiah, K., Du, B., Chang, M., Yang, P., Newman, R. A., Cordon-Cardo, C., Thaler, H. T. and Dannenberg, A. J. (2005): Celecoxib inhibits prostate cancer growth: Evidence of a cyclooxygenase-2-independent mechanism. Clin. Cancer Res. 11, 1999-2007.

Pereg, D. and Lishner, M. (2005): Non-steroidal anti-inflammatory drugs for the prevention and treatment of cancer. J. Intern. Med. 258, 115-123.

Pereira, P. D., Lopes, C. C., Matos, A. J. F., Pinto, D., Gartner, F., Lopes, C. and Medeiros, R. (2009): Influence of catechol-o-methyltransferase (COMT) genotypes on the prognosis of canine mammary tumors. Vet. Pathol. 46, 1270-1274.

Rai, R. B., Saminathan, M., Dhama, K., Ranganath, G. J., Murugesan, V., Kannan, K., Pavulraj, S., Gopalakris, A. and Suresh, C. (2014): Histopathology and immunohistochemical expression of n-methyl-n-nitrosourea (NMU) induced mammary tumours in Sprague-Dawley rats. Asian J. Anim. Vet. Adv. 9, 621-640.

Ralph, S., Pritchard, R., Rodríguez-Enríquez, S., Moreno-Sánchez, R. and Ralph, R. (2015): Hitting the bull's-eye in metastatic cancers - NSAIDs elevate ROS in mitochondria, inducing malignant cell death. Pharmaceuticals (Basel) 8, 62-106.

Rao, P. and Knaus, E. E. (2008): Evaluation of nonsteroidal anti-inflammatory drugs (NSAIDs): cyclooxygenase (COX) inhibition and beyond. J. Pharm. Pharm. Sci. 11, 81-110.

Rayburn, E. R., Ezell, S. J. and Zhang, R. (2009): Anti-inflammatory agents for cancer therapy. Mol. Cell. Pharmacol. 1, 29-43.

Rehman, M. U., Tahir, M., Khan, A. Q., Khan, R., Oday, O. H., Lateef, A., Hassan, S. K., Rashid, S., Ali, N., Zeeshan, M. and Sultana, S. (2014): D-limonene suppresses doxorubicin-induced oxidative stress and inflammation via repression of COX-2, iNOS, and NF B in kidneys of Wistar rats. Exp. Biol. Med. 239, 465-476.

Roberts, E. S., Van Lare, K. A., Marable, B. R. and Salminen, W. F. (2009): Safety and tolerability of 3-week and 6-month dosing of Deramaxx ${ }^{\circledR}$ (Deracoxib) chewable tablets in dogs. J. Vet. Pharmacol. Ther. 32, 329-337.

Sanchez de Miguel, L., de Frutos, T., Gonzalez-Fernandez, F., del Pozo, V., Lahoz, C., Jimenez, A., Rico, L., Garcia, R., Aceituno, E., Millas, I., Gomez, J., Farre, J., Casado, S. and LopezFarre, A. (1999): Aspirin inhibits inducible nitric oxide synthase expression and tumor necrosis factor-alpha release by cultured smooth muscle cells. Eur. J. Clin. Invest. 29, 93-99.

Schreck, R., Rieber, P. and Baeuerle, P. A. (1991): Reactive oxygen intermediates as apparently widely used messengers in the activation of the NF- $\mathrm{kB}$ transcription factor and HIV-1. EMBO J. 10, 2247-2258.

Shi, Y. (2001): A structural view of mitochondria-mediated apoptosis. Nat. Struct. Mol. Biol. 8, 394-401.

Simon, D., Schoenrock, D., Baumgärtner, W. and Nolte, I. (2006): Postoperative adjuvant treatment of invasive malignant mammary gland tumors in dogs with Doxorubicin and Docetaxel. J. Vet. Intern. Med. 20, 1184-1190.

Smalley, M. J. (2010): Isolation, culture and analysis of mouse mammary epithelial cells. In: Ward, A. and Tosh, D. (eds) Mouse Cell Culture, 1st edition. Springer Science \& Business Media, LCC. pp. 139-170.

Souza, C. H. M., Toledo-Piza, E., Amorin, R., Barboza, A. and Tobias, K. M. (2009): Inflammatory mammary carcinoma in 12 dogs: Clinical features, cyclooxygenase-2 expression, and response to piroxicam treatment. Can. Vet. J. 50, 506-510.

Todorova, I., Simeonova, G., Simeonov, R. and Dinev, D. (2005): Efficacy and toxicity of doxorubicin and cyclophosphamide chemotherapy in dogs with spontaneous mammary tumours. TJS 3, 51-58. 
Ustun Alkan, F., Bakirel, T., Ustuner, O. and Yardibi, H. (2014): In vitro effects of doxorubicin and deracoxib on oxidative-stress-related parameters in canine mammary carcinoma cells. Acta Vet. Hung. 62, 372-385.

Ustun Alkan, F., Ustuner, O., Bakirel, T., Cinar, S., Erten, G. and Deniz, G. (2012): The effects of piroxicam and deracoxib on canine mammary tumour cell line. Sci. World J. 2012, 1-8.

van Wijngaarden, J., Van Beek, E., Van Rossum, G., Van Der Bent, C., Hoekman, K., Van Der Pluijm, G., Van Der Pol, M. A., Broxterman, H. J., Van Hinsbergh, V. W. M. and Löwik, C. W. G. M. (2007): Celecoxib enhances doxorubicin-induced cytotoxicity in MDA-MB231 cells by NF-kB-mediated increase of intracellular doxorubicin accumulation. Eur. J. Cancer 43, 433-442.

Wolfe, L. G., Smith, B. B., Toivio-Kinnucan, M. A., Sartin, E. A., Kwapien, R. P., Henderson, R. A. and Barnes, S. (1986): Biologic properties of cell lines derived from canine mammary carcinomas. J. Natl Cancer Inst. 77, 783-792.

Wolfesberger, B., Hoelzl, C., Walter, I., Reider, G. A., Fertl, G., Thalhammer, J. G., Skalicky, M. and Egerbacher, M. (2006): In vitro effects of meloxicam with or without doxorubicin on canine osteosarcoma cells. J. Vet. Pharmacol. Ther. 29, 15-23. 